\title{
Study on the Bending Moment of waist beam for the Excavation Retaining Structure
}

\author{
Yongqiang Lei ${ }^{1, a}$, Jiangang Han ${ }^{2, b}$, Jiacan Wang ${ }^{3, c}$ and Yuan Chen ${ }^{4, d}$ \\ ${ }^{1}$ College of Civil Engineering and Architecture , Hainan University, Haikou, China \\ ${ }^{2}$ College of Civil Engineering and Architecture, Hainan University, Haikou, China \\ ${ }^{3}$ Xiamen municipal engineering design institute co., Ltd, Xiamen, China \\ ${ }^{3}$ Hainan nonferrous engineering survey and design institute, Haikou, China \\ a529050710@qq.com, ${ }^{\text {bxianhjg@163.com, }{ }^{c} 297168904 @ q q . c o m,{ }^{d} 359951679 @ q q . c o m}$
}

Keywords: excavation retaining structure. waist beam. bending moment. inverted beam method. Abstract. The pile-anchor supporting system is wildly used in the excavation supported system, and waist beams play an important role in the supported system. If the waist beam is destroyed, it may lead to the collapse of the retaining structure. But now, the designers tend to ignore the specifically designed for it, some one use the single span beam to design the waist beam, this is too conservative. The others use the continuous beam to calculate, although it is reasonable in the ideal state, but there are lots of uncertain factors on the construction site, which will be some risk. So we will give some reasonable suggestions by comparing several common waist beams’ calculation method.

\section{Introduction}

At present, in the excavation supporting engineering, the pile-anchor supporting system application is very extensive, it consists of piles, waist beams and the anchor. The destruction of waist beam will lead to the collapse of the retaining structure. So the waist beam is very important to the pile-anchor supporting system. But people often ignore the design for it, this is very dangerous. So we will give some reasonable suggestions by comparing several common waist beams’ calculation methods.

\section{Bending Moment Calculation of Waist Beam}

The calculation of the "one pile one anchor" type of waist beam. In the "one pile one anchor" type of waist beam, the space of anchors and piles is equal. It have four kinds of calculation methods.

Method 1: we don't consider the filling between the pile and the waist beam, and according to the single span beam to calculate. We can use the pile or anchor cable as the bearing.

If we use the pile as the bearing, simplifying the anchor cable as a concentrated load, the calculating diagram of waist beam as shown in fig.1. The bending moment diagram is shown in fig.2. If we use the anchor cable as the bearing, simplifying the pile as a concentrated load. the calculating diagram of waist beam as shown in fig. 1 too. $F$ is the anchor cable's force, $d$ is the anchor's spacing.

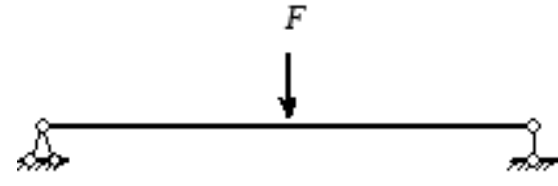

Fig.1. Simple diagram for calculating

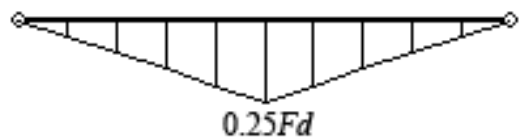

Fig.2. Bending moment diagram

So, According to the result of method 1 , the soil side and the inside of the excavation of the waist beam's maximum bending moment value should be $0.25 \mathrm{Fd}$.

Method 2: we don't consider the filling between the pile and the waist beam, and according to the five span continuous beam to calculate.

If we use the pile as the bearing, simplifying the anchor cable as a concentrated load, the calculating diagram of waist beam as shown in fig.3, the bending moment diagram is shown in fig.4. 


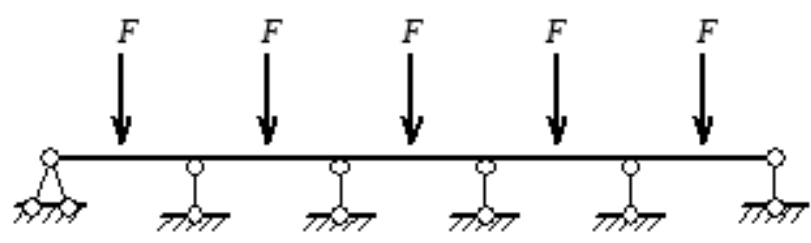

Fig.3. Simple diagram for calculating

If we use the anchor cable as the bearing, simplifying the pile's force for a concentrated load, it's value is $F$. The calculating diagram and bending moment diagram are shown in fig.3 and fig.5.

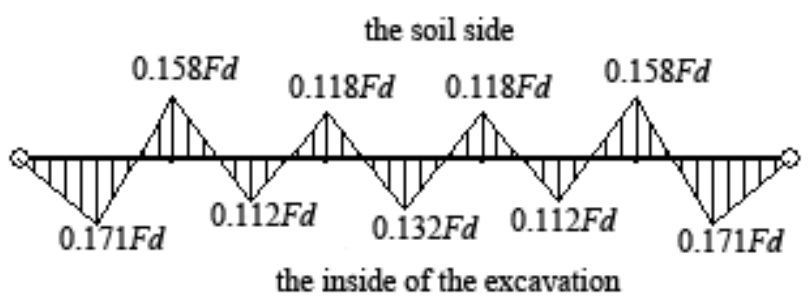

Fig.4. Bending moment diagram

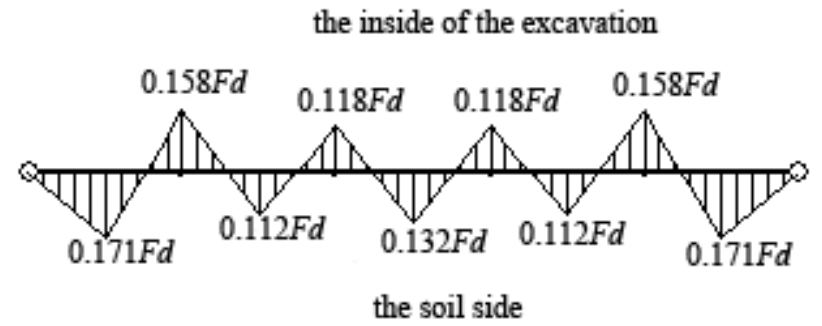

Fig.5. Bending moment diagram

So, According to the result of method two, the soil side and the inside of the excavation for the waist beam's maximum bending moment value should be $0.171 \mathrm{Fd}$.

Method 3: we consider the filling between the pile and the waist beam, simplifying them as the uniform load. and use the anchor cable as the bearing, We can use the single span beam to calculate. The value of $q$ is $F / d$.The calculating diagram is shown in fig.6, the bending moment diagram is shown in fig.7. $q$ is the function of the pile and the filler.

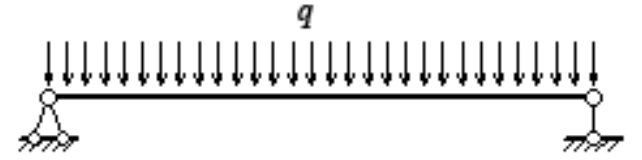

Fig.6. Simple diagram for calculating

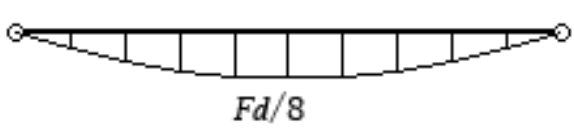

Fig.7. Bending moment diagram

According to the result of method 3 , the soil side and the inside of the excavation for the waist beam's maximum bending moment value should be $\mathrm{Fd} / 8$.

Method 4: we consider the bearing and the load as method 3. And use the continuous beam to calculate.The calculating diagram and the bending moment diagram is shown in fig.8 and fig.9.

the soil side

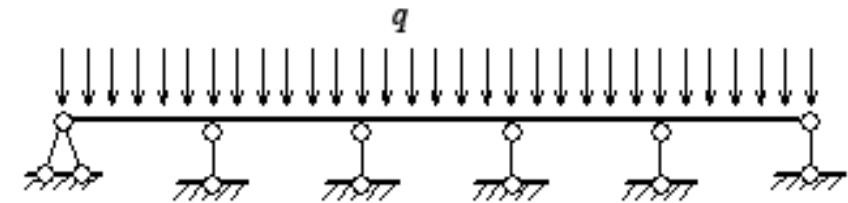

Fig.8. Simple diagram for calculating

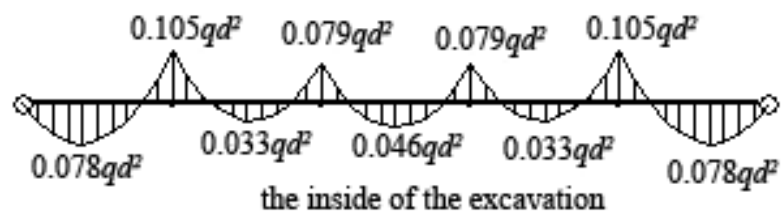

Fig.9. Bending moment diagram

According to the result of this method, the soil side and the inside of the excavation for the waist beam's maximum bending moment value should be $0.105 \mathrm{Fd}$.

The calculation of the "two pile one anchor" type of waist beam. In the "two pile one anchor" type of waist beam, the spacing of the anchor cable is two times that of pile's. This type of waist beam has four kinds of calculation methods.

Method 1: we don't consider the filling between the pile and the waist beam, and use the anchor cable or pile as the bearing, then, simplify the function of the pile or the anchor cable for the concentrated load. We can use the single span beam to calculate.

If we use piles on both sides of the cable as the bearing, simplifying the anchor cable as a concentrated load, the result is same to the method 1 of the "one pile one anchor" type of waist beam. 
If we use the anchor cable as the bearing, simplifying the pit for a concentrated load, $Q$ is the pile's force. The calculating diagram and bending moment diagram is shown in fig.10 and fig.11.

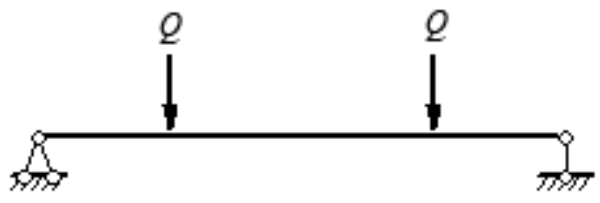

Fig.10. Simple diagram for calculating

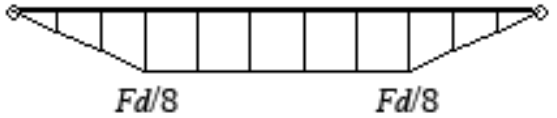

Fig.11. Bending moment diagram

According to the result of this method, the soil side and the inside of the excavation for the waist beam's maximum bending moment value is $\mathrm{Fd} / 8$.

Method 2: we don't consider the filling, simplifying the function of the pile or the anchor cable for a concentrated load. We can use the five span continuous beam to calculate.

If we use the piles as the bearing, simplifying the function of the anchor cable for a concentrated load, the calculating diagram is shown in fig.12, the bending moment diagram is shown in fig.13.

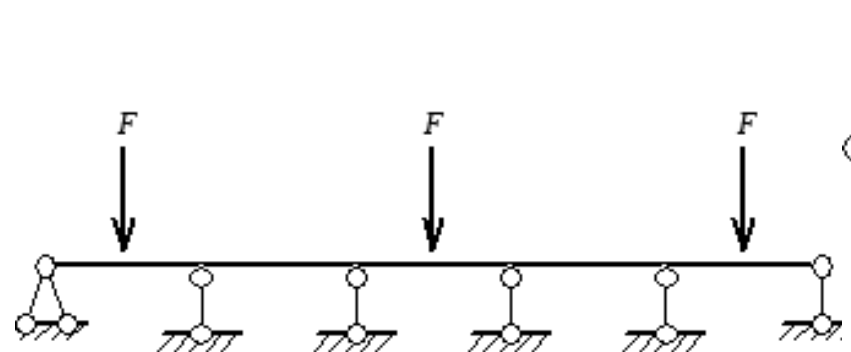

Fig.12. Simple diagram for calculating

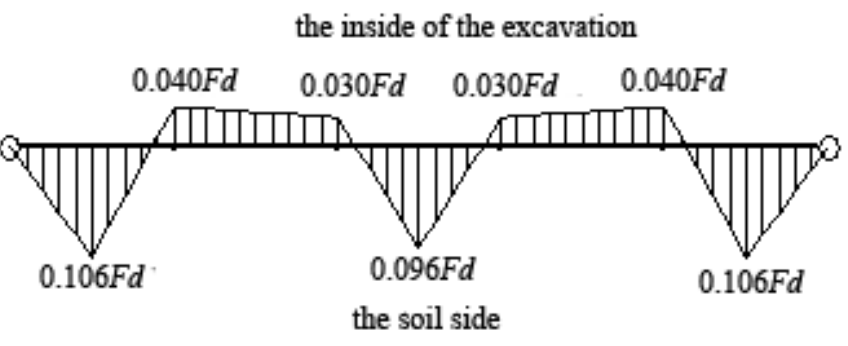

Fig.13. Bending moment diagram

If we use the anchor cable as the bearing and simplify the function of the piles for the concentrated load, The calculating diagram is shown in fig.14, the bending moment diagram is shown in fig.15.

the soil side

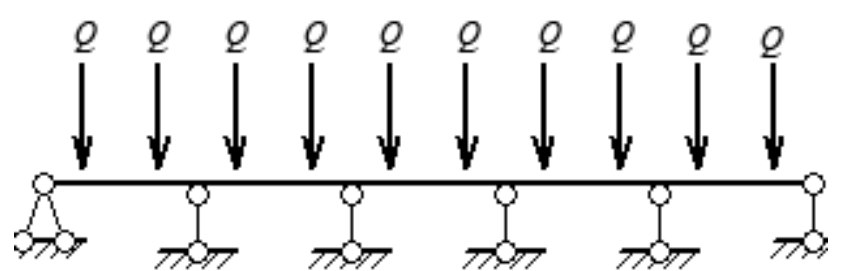

Fig.14. Simple diagram for calculating

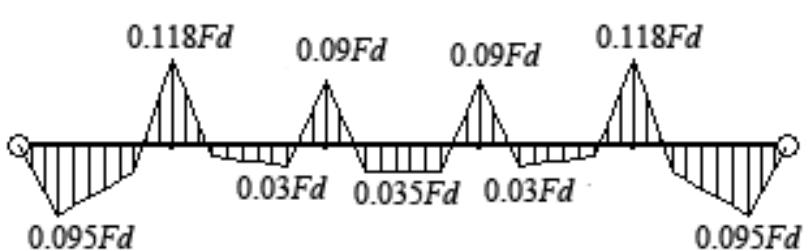

the inside of the excavation

Fig.15. Bending moment diagram

According to the result of method 2, the soil side and the inside of the excavation for the waist beam's maximum bending moment value is $0.118 \mathrm{Fd}$.

Method 3: it is like the method 3 of the "one pile one anchor" type, the result should be $\mathrm{Fd} / 8$.

Method 4: it is like the method 4 of the "one pile one anchor" type, the result should be $0.105 \mathrm{Fd}$.

\section{Example}

The south of the excavation's second phase close to the first phase, the east and the west close to a road, on the north side, there are some houses. The floor area is about $4600 \mathrm{~m}^{2}$, the building area is about $43100 \mathrm{~m}^{2}$, there are eight storeys on the ground, and there are three storeys under the ground. The excavation is rectangular, the length is $95 \mathrm{~m}$, the width is $50 \mathrm{~m}$, the depth is $17 \mathrm{~m}$. In the excavation supporting system, the piles' diameter is $800 \mathrm{~mm}$, the spacing is $1600 \mathrm{~mm}$, the depth of build-in is 4.5 $\mathrm{m}$, the anchorage force of anchor cable is $300 \mathrm{kN}$. On the south side, the form of support is the "one pile one anchor" type, and on the north side, the form of support is the "two pile one anchor" type.

For this engineering, Calculation results of the south and north's waist beam are shown in table 1. 
Table 1 Calculation results of the south and north's waist beam

\begin{tabular}{|c|c|c|c|c|c|c|c|c|c|}
\hline Type & $\begin{array}{l}\text { Working } \\
\text { condition }\end{array}$ & Method & $\begin{array}{l}\text { Soil side } \\
/ \mathrm{kN} \cdot \mathrm{m}\end{array}$ & $\begin{array}{l}\text { Inside of } \\
\text { the beam } \\
/ \mathrm{kN} \cdot \mathrm{m}\end{array}$ & Type & $\begin{array}{l}\text { Working } \\
\text { condition }\end{array}$ & Method & $\begin{array}{l}\text { Soil } \\
\text { side } \\
/ \mathrm{kN} \cdot \mathrm{m} \\
\end{array}$ & $\begin{array}{l}\text { Inside of } \\
\text { the beam } \\
/ \mathrm{kN} \cdot \mathrm{m}\end{array}$ \\
\hline \multirow{6}{*}{$\begin{array}{c}\text { (south) } \\
\text { One } \\
\text { pile } \\
\text { one } \\
\text { anchor }\end{array}$} & \multirow{3}{*}{$\begin{array}{c}\text { Don't } \\
\text { consider } \\
\text { the } \\
\text { filling }\end{array}$} & Method 1 & 120 & 120 & \multirow{6}{*}{$\begin{array}{l}\text { (north) } \\
\text { Two } \\
\text { pile } \\
\text { one } \\
\text { anchor }\end{array}$} & \multirow{3}{*}{$\begin{array}{l}\text { Don't } \\
\text { consider } \\
\text { the } \\
\text { filling }\end{array}$} & Method 1 & 120 & 120 \\
\hline & & Method 2 & 82.08 & 82.08 & & & Method 2 & 113.28 & 113.28 \\
\hline & & suggestion & 101.04 & 101.04 & & & $\begin{array}{l}\text { suggestio } \\
n\end{array}$ & 120 & 120 \\
\hline & \multirow{3}{*}{$\begin{array}{l}\text { Consider } \\
\text { the filling }\end{array}$} & Method 3 & 60 & 60 & & \multirow{3}{*}{$\begin{array}{l}\text { Consider } \\
\text { the filling }\end{array}$} & Method 3 & 120 & 120 \\
\hline & & Method 4 & 50.4 & 50.4 & & & Method 4 & 100.8 & 100.8 \\
\hline & & suggestion & 60 & 60 & & & $\begin{array}{l}\text { suggestio } \\
\text { n }\end{array}$ & 120 & 120 \\
\hline
\end{tabular}

1) For the "one pile one anchor" type of waist beam, when don't consider the filling, the value of method 2 is $31.6 \%$ less than the method 1 , so the result of method 2 is more economic, in ideal state, the result of method 2 is more reasonable. But there is no ideal state, a lot of uncertain factors will produce a great impact on the force performance of waist beam. So, it is recommended that the result should be the average value of method 1 and method 2 . When consider the filling, the value of method 4 is $16 \%$ less than method 3, In order to ensure the safety, we suggest use the method 3 to calculate.

2) For the "two pile one anchor" type of waist beam, when we don't consider the filling, the value of method 2 is $5.6 \%$ smaller than method 1 ; when we consider the filling, the value of method 4 is $16 \%$ smaller than method 3 . So in order to ensure the safety of the excavation, we suggest according to the method 1 and method 3 to calculate.

\section{Conclusions}

This paper is aimed at the "one pile one anchor" and "two pile one anchor" type of waist beam, the conclusions as follows.

1) For the "one pile one anchor" type of waist beam. When don't consider the filling, we can use the pile as the bearing, simplify the anchor as a concentrated load, according to the single span beam to calculate, the bending moment value is reduced by $15.8 \%$, the result will be used to design the waist beam. When we consider the filling, and we use the anchor cable as the bearing, simplify the function of the pile and the filler for the uniform load, the single span beam is used to calculate.

2) For the "two pile one anchor" type of waist beam. when don't consider the filling, we can use piles on both sides of the cable as the bearing, simplify the function of the anchor as a concentrated load, use the single span beam to calculate, we can get the bending moment to design the waist beam. When consider the filling, we can use the anchor cable as the bearing, simplify the function of the pile and the filler for the uniformly distributed load, according to the single span beam to calculate.

\section{Acknowledgement}

This work was financially supported by the Hainan Province Natural Science Foundation of China (511108).

\section{References}

[1] Macnab, A. (2002) Earth Retention Systems Handbook, McGraw-Hill, New York, pp. 319-322.

[2] Goldberg, D.T., Jaworski, W.E. and Gordon, M.D. (1976) "Lateral Support Systems and Underpinning”, FHWA-RD-75-128,pp 118-121. 
[3] Guobin Liu, Weidong Wang. (2009) Excavation engineering manual. Bei Jing: China Architecture \& Building Press. (In Chinese)

[4] Jie Song. (2010) Simplified calculation method of ring beam stiffness on retaining piles. Construction \& Design for Project:89-92. (In Chinese)

[5] Zigang Shi, Wei Wei. (2012) Research on the middle beam substitution in retaining and protecting for deep foundation excavation. Industrial Construction: 447-450. (In Chinese) 